\title{
Adolfo DuCKe - O GRANDe EXPLORAdor e bOtÂNICO Da Amazôni a brasilleIra no SÉCUlO XX
}

Ar el evânci a da contri bui ção do natural i st a Adol fo Ducke é ref er ênci a constant e nos est udos sobre a di versi dade veget al na Amazôni a. É surpreendente o vol ume de trabal hos científicos produzi dos ao longo de mai s de cinco décadas, quando comtanto sacrifício percorreu vastos espaços da mai or fl oresta pl uvi al neot ropical. De fato umdesbravador, naquel e tempo que singrar rios amazôni cos embusca do conhecimento da flora era uma aventura por demai s arriscada e chei a surpresas.

Ducke era natural de Trieste, hoj e norte da I tál i a, e foi contratado em 1899 pel o Museu Paraense para atuar na Seção de Zool ogi a. Embora envol vi do di retamente em estudos ent omológi cos, desde a sua chegada à Amazôni a também demonstrou inter esse pel a fl ora, parti cul ar mente emest udos taxonôm cos de espéci es arbór eas. Este interesse o l evou a uma gradual transformação emsuas investi gações, que a partir de 1915 passarama ser excl usi vament e na ár ea de botâni ca. Post eri or mente, coma sua transf er ênci a para $0 \mathrm{~J}$ ardi $m$ Botâni co do Ri o de J anei ro, entre 1918 e 1945 real izou as suas grandes vi agens para os estudos da fl ora, percorrendo os princi pai s ri os e af I uentes da baci a amazônica.

Os resul tados de seus estudos sobre pl antas amazôni cas for amdi vul gados emcerca de 120 publicações, onde for am descritos aproxi madamente 900 novas espéci es e 50 novos gêneros. Uma produção ci entífi ca que denota uma grande capacidade de trabal ho e uma das mai ores contri bui ções para o conheci ment 0 da di versi dade bi ol ógi ca amazôni ca real i zada por umci entista no sécul o XX. Nos pri mei ros vol umes da Rodri guési a podemos conhecer os rel at óri os de vi agemque Ducke envi ava para 0 Jardi mBotâni co do Ri 0 de J anei ro. At ravés de textos escritos de forma primorosa e comriquezas de detal hes que ultrapassamo conheci ment o botâni co e nos apresenta umpanorama compl et 0 , desde a vi da do homem ri bei ri nho at é as di fi cul dades de se fazer ci ênci a naquel a época.

Al émda produção científica, i mprescindí vel para o conheci ment o da fl ora amazôni ca, 0 principal I egado de Ducke foi 0 grandi oso acervo ci entíf i co que hoj e enri quece o herbári o do Inst i tut 0 de Pesqui sas J ar di m Botâni co do Ri o de J anei $r o$ (RB). Essenci al ment e umpesqui sador de campo, foi ai nda incumbi do de organi zar umprograma de col et as de plantas vi vas para 0 arboret 0 desta inst i tui ção. Nos di as at uai $s$, est a col eção é reput ada como uma das mai $s$ represent at i vas para conservação ex si tu de pl antas amazônicas.

Ducke pri vi l egi ava 0 estudo das $\mathrm{pl}$ antas emseu ambi ente nat ural, o que exi gi a cont at os recorrentes comcertos trechos da regi ão amazôni ca para a obt enção compl et a de dados e materi al botâni co das espéci es emestudo. Foi este procedi ment o metodol ógi co que I he per mi ti u um conheci ment o bastante detal hado das vari ações fi si onômi cas e florísticas na baci a amazônica. Tendo al cançado este conheci ment o i ni gual ável sobre a veget ação, Ducke propôs a pri mei ra anál i se consistente sobre a fi togeografia desta região. Até hoj e, a sua proposta, el aborada emcolaboração com George A. Bl ack, é considerada uma das mais fundament adas com dados botâni cos.

Ainda hoje os estudos de Ducke conti nuama infl uenci ar as pesqui sas na Amazôni a. Outros botâni cos procuramtri I har os cam nhos per corridos pel o grande expl or ador, col et ando novas amostras de plant as ou repetindo suas anál i ses comtécnicas e ferrament as mai $s$ 
moder nas. Os i nventári os int ensi vos emcertas I ocal i dades de al ta di ver si dade bi ol ógi ca tem si do umoutro cami nho dos segui dores de Ducke. Nesta I inha de invest i gação, não é uma si mpl es coi nci dênci a que umdos proj et os mai s i mportantes vemsendo desenvol vi do na Reserva Ducke, nos arredores de Manaus. Trata-se de umesforço concentrado para conhecer a flora de umtrecho da Amazôni a Central, onde já foramamstradas cerca de duas mi I espéci es de pl ant as.

Sem dúvi da o conheci ment 0 da fl ora, princi pal ment e emlocai s de al ta di versidade, é 0 passo i ni ci al para estudos mul ti di sci pl i nares. Já foi demnnstrado que est a é uma estrat égi a ef i ci ent e para acel er ar as anál i ses emní vei s de comuni dade e de ecossi st ema. Não é por acaso que nos trópicos, mai s preci sament e emfl or est as tropi cai s, uma si gni fi cati va parte do conheci ment o ecol ógi co vemsendo obt i do em l ocai s coma fl or a cat al ogada e di sponí vel em manuai s. Áreas bemconheci das emterms fl orísticos tambémt ornampossí vei s anál i ses comparat i vas para def i ni ção de pri ori dades de conservação.

Nest e cont ext 0 , a publ i cação dos tratament os taxonômi cos das faḿl I as ocorrentes na Reserva Ducke é oportuna para apoi ar o increment o de novos estudos emuma área tão crítica para a conservação. Sendo assi $m, 0$ J ardi m Botâni co do Ri o de J anei $r o$, at ravés da Rodri guési a, rende umtributo à memóri a de Adolfo Ducke e af irma sua renovada adesão aos i deai s do il ust re botâni co, na conti nui dade de seu extraordi nári 0 esf or ço de grande expl or ador da fl ora amazônica.

Har ol do Caval cante de Li ma

Pesqui sador do J BRJ 